\title{
National Cancer Institute Terminology
}

National Cancer Institute

\section{Source}

National Cancer Institute. National Cancer Institute Terminology. NCI Thesaurus. Code C143048.

Terminology sets that are designed to fulfill the need to have consistent coding, analysis, and data sharing across a broad range of National Cancer Institute $(\mathrm{NCl})$ resources. 